(c) Волынкина А.С., Рязанова А.Г., Русанова Д.В., Куличенко А.Н., 2021

УДК 616-036.22

\title{
Проблема ДНК(РНК)-контаминации в лаборатории при проведении диагностики COVID-19 методом ПЦР
}

\author{
А.С. Волынкина, А.Г. Рязанова, Д.В. Русанова, А.Н. Куличенко \\ ФКУЗ «Ставропольский противочумный институт» Роспотребнадзора, \\ ул. Советская, д. 13-15, г. Ставрополь, 355035, Российская Федерация
}

\section{Резюме}

Введение. При проведении исследований клинического материала методом ПЦР на наличие РНК коронавируca SARS-CoV-2 в начале пандемии COVID-19 лабораторная служба в России и зарубежных странах столкнулась с проблемами точности диагностики, получением ложноотрицательных, ложноположительных и сомнительных результатов.

Цель работы - анализ литературных источников по проблеме ложноположительных и сомнительных результатов исследования клинического материала на COVID-19 методом ПЦР.

Материалы и методы. Для анализа отобраны российские и зарубежные статьи, посвященные вопросам организации лабораторной диагностики новой коронавирусной инфекции, проблемным вопросам лабораторной диагностики методом ПЦР SARS и MERS и общим проблемам ДНК-контаминации в ПЦР-лаборатории (2012-2020 гг.), а также действующие нормативно-методические документы, регламентирующие проведение лабораторной диагностики новой коронавирусной инфекции методом ПЦР.

Результаты. Проанализированы факторы, приводящие к контаминации нуклеиновыми кислотами в лабораториях, выполняющих массовые исследования клинического материала молекулярно-генетическими методами на наличие PHK нового коронавируса SARS-CoV-2 в условиях пандемии COVID-19. Основными причинами, способствующими возникновению контаминации, являются большие объемы исследований, накопление в лаборатории образцов клинического материала, увеличение количества отходов, содержащих продукты амплификации. Перекрестная контаминация происходит вследствие технических ошибок при выполнении лабораторных манипуляций на этапах пробоподготовки и обеззараживания материала, выделения РНК, внесения проб кДНК/РНК, положительных контрольных образцов в реакционную смесь. Загрязнение рабочих зон лаборатории ампликонами, возникающее при открытии пробирок и планшетов, содержащих продукты ПЦР, - главная причина тотальной контаминации в лаборатории. Признаками перекрестной контаминации являются увеличение доли положительных проб с низкими значениями порогового цикла и выявление положительного сигнала в отрицательных контрольных образцах этапов выделения и амплификации. Получение положительного результата для всех проб в постановке, включая отрицательные контрольные образцы, свидетельствует о «тотальной контаминации» в лаборатории. Помимо контаминации, к ложноположительным результатам анализа может приводить образование неспецифических продуктов ПЦР на поздних циклах реакции и неспецифическая флуоресценция реакционной смеси, возникающая при несоблюдении температурного режима хранения реактивов.

Заключение. Для предотвращения контаминации в лаборатории, выполняющей исследования методом ПЦР, необходим строгий контроль соблюдения поточности движения исследуемого материала и медицинских отходов, регулярный анализ частоты положительных ответов, обязательное проведение внутрилабораторного контроля качества исследований и ДНК(РНК)-контаминации.

Ключевые слова: ПЦР, лабораторная диагностика, контаминация, SARS-CoV-2, COVID-19.

Для цитирования: Волынкина А.С., Рязанова А.Г., Русанова Д.В., Куличенко А.Н. Проблема ДНК(РНК)-контаминации в лаборатории при проведении диагностики COVID-19 методом ПЦР // Здоровье населения и среда обитания. 2021. Т. 29. № 7. С. 76-81. doi: https://doi.org/10.35627/2219-5238/2021-29-7-76-81

Сведения об авторах:

$\triangle$ Волынкина Анна Сергеевна - канд. биол. наук, и.о. заведующего лабораторией диагностики вирусных инфекций; е-таil: volyn444@ mail.ru; ORCID: https://orcid.org/0000-0001-5554-5882.

Рязанова Алла Геннадьевна - канд. мед. наук, зав. лабораторией сибирской язвы; e-mail: anthraxlab.stv@mail.ru; ORCID: https://orcid.org/ 0000-0002-5196-784X.

Русанова Диана Владимировна - канд. мед. наук, зав. научно-производственной лабораторией препаратов для диагностики особо опасных и других инфекций; e-mail: dianarus2010@rambler.ru; ORCID: https://orcid.org/0000-0003-2229-6570.

Куличенко Александр Николаевич - д-р. мед. наук, профессор, член-корреспондент PAH, директор; е-mail: kulichenko_an@list.ru; ORCID: https://orcid.org/0000-0002-9362-3949.

Информация о вкладе авторов: А.С. Волынкина - обзор литературных источников, написание текста рукописи; А.Г. Рязанова, Д.В. Русанова - анализ практического опыта проведения ПЦР-скрининга образцов на наличие PHК нового коронавируса SARSCoV-2 в период пандемии COVID-19; А.Н. Куличенко - составление общей структуры работы.

Финансирование: исследование проведено за счет базового финансирования ФКУЗ «Ставропольский противочумный институт» Роспотребнадзора.

Конфликт интересов: авторы заявляют об отсутствии конфликта интересов.

Статья получена: 28.12.20 / Принята к публикации: 07.07.21 / Опубликована: 30.07.21

\section{The Problem of DNA/RNA Contamination in the Laboratory during PCR Testing for COVID-19}

Anna S. Volynkina, Alla G. Ryazanova, Diana V. Rusanova, Alexandr N. Kulichenko Stavropol Research Anti-Plague Institute, 13-15 Sovetskaya Street, Stavropol, 355035, Russian Federation Summary

Introduction. When conducting PCR (polymerase chain reaction) testing of biospecimens for SARS-CoV-2 RNA at the beginning of the COVID-19 pandemic, the laboratory service in Russia and foreign countries encountered problems related to the accuracy of diagnostics and obtaining false negative, false positive, and dubious results.

The objective of this work was to analyze current literature on the problem of false positive and dubious results of RT-PCR testing for COVID-19.

Material and methods. We selected Russian and foreign English-language publications devoted to organization of laboratory diagnostics of the novel coronavirus disease, challenges of PCR testing for SARS and MERS, and general issues of DNA contamination in a PCR laboratory for 2012-2020. We also reviewed current regulations and guidelines for COVID-19 diagnostic testing. 
Results. The analysis of factors leading to contamination of specimens with nucleic acids in the laboratories performing massive COVID-19 PCR testing during the pandemic showed that the main reasons for contamination included a large number of tests, accumulation of samples in the laboratory, and the increased amount of wastes containing amplification products. Cross-contamination occurs due to technical errors in the course of laboratory manipulations at the stages of sample preparation and inactivation, RNA isolation, and addition of CDNA/RNA or positive control samples to the reaction mixture. Pollution of laboratory working areas with amplicons arising from the opening of tubes and plates containing PCR products is the main cause of total contamination in the laboratory. Signs of cross-contamination include the increase in the proportion of positive samples with low threshold cycle values and detection of a positive signal from negative control samples at RNA isolation and amplification stages. A positive result for all samples in a round, including negative control samples, is a marker of "total contamination" in the laboratory. In addition to contamination, formation of nonspecific PCR products at late reaction cycles and nonspecific fluorescence of the reaction mixture, which occurs when reagent storage temperatures are not observed, may also lead to false positive results.

Conclusion. To prevent contamination in a PCR laboratory, strict control over the flow of test samples and medical wastes, regular analysis of the frequency of positive test results, and mandatory laboratory quality control of testing and DNA/ RNA contamination are compulsory.

Keywords: RT-PCR, laboratory diagnostics, contamination, SARS-CoV-2, COVID-19.

For citation: Volynkina AS, Ryazanova AG, Rusanova DV, Kulichenko AN. The problem of DNA/RNA contamination in the laboratory during PCR testing for COVID-19. Zdorov'e Naseleniya i Sreda Obitaniya. 2021; 29(7):76-81. (In Russ.) doi: https://doi. org/10.35627/2219-5238/2021-29-7-76-81

Author information:

$\triangle \quad$ Anna S. Volynkina, Cand. Sci. (Biol.), Head of the Diagnostic Virology Laboratory Stavropol Research Anti-Plague Institute; e-mail: volyn444@mail.ru; ORCID: https://orcid.org/0000-0001-5554-5882.

Alla G. Ryazanova, Cand. Sci. (Med.), Head of the Anthrax Laboratory Stavropol Research Anti-Plague Institute; e-mail: anthraxlab.stv@ mail.ru; ORCID: https://orcid.org/0000-0002-5196-784X.

Diana V. Rusanova, Cand. Sci. (Med.), Head of the Research and Production Laboratory of Preparations for Diagnosis of Highly Hazardous and Other Infections Stavropol Research Anti-Plague Institute; e-mail: dianarus2010@rambler.ru; ORCID: https://orcid.org/0000-00032229-6570

Alexandr N. Kulichenko, Dr. Sci. (Med.), Prof., Corresponding Member, Russian Academy of Sciences, Director, Stavropol Research AntiPlague Institute; e-mail: kulichenko_an@list.ru; ORCID: https://orcid.org/0000-0002-9362-3949.

Autor contribution: Volynkina A.S. did a literature review and wrote the manuscript; Ryazanova A.G. and Rusanova D.V. analysed practical experience in RT-PCR testing for SARS-CoV-2 during the pandemic of COVID-19; Kulichenko A.N. drew up a general structure of work; all authors discussed the results and contributed to the final manuscript.

Funding: The study was conducted at the expense of basic funding of the Stavropol Research Anti-Plague Institute.

Conflict of interest: The authors declare that there is no conflict of interest.

Received: December 28, 2020 / Accepted: July 07, 2021 / Published: July 30, 2021

Введение. COVID-19 - острая респираторная инфекция, вызванная коронавирусом SARS-CoV-2 (2019-nCoV), ассоциированная с высоким уровнем летальности среди лиц старшей возрастной группы и с сопутствующими заболеваниями сердечно-сосудистой и эндокринной систем. Инфекция в короткий срок распространилась по всему миру и приобрела характер пандемии $[1,2]$. По состоянию на 23 июля 2021 г. в мире зарегистрировано более 186 млн случаев новой коронавирусной инфекции, в России - свыше 6 млн случаев.

Новый коронавирус SARS-CoV-2 относится к роду Betacoronavirus, подроду Sarbecovirus, генетически близок к коронавирусам SARS-CoV и MERS-CoV (возбудителями SARS и MERS). Геном вируса представлен одноцепочечной РНК позитивной полярности, включает один линейный сегмент размером около 30000 нуклеотидных оснований [3-7]. Коронавирус SARS-CoV-2 предварительно отнесен ко II группе патогенности, в соответствии с принятой в Российской Федерации классификацией биологических агентов, вызывающих болезни человека.

Лабораторная диагностика - важная составляющая часть комплекса мероприятий, направленных на борьбу с распространением COVID-19. Массовое тестирование населения на наличие PHK нового коронавируса SARS-CoV-2 необходимо для своевременного выявления больных новой коронавирусной инфекцией среди людей с симптомами ОРВИ и пневмонии, обследования контактных, активного выявления бессимптомных носителей вируса. Получение достоверных результатов лабораторных исследований на COVID-19 в короткие сроки имеет существенное значение для повышения эффективности мероприятий, направленных на предупреждение распространения инфекции.

Диагностика COVID-19, основанная на детекции PHK коронавируса SARS-CoV-2 в биологичес- ком материале человека методом полимеразной цепной реакции с обратной транскрипцией (ПЦР или ОТ-ПЦР), получила наиболее широкое распространение.

ОТ-ПЦР - высокочувствительный тест, широко применяющийся для лабораторной диагностики вирусных инфекций, является «золотым стандартом» для специфической лабораторной диагностики COVID-19 [8-12]. В то же время при проведении исследований клинического материала методом ПЦР на наличие PHK коронавируса SARS-CoV-2 в начале пандемии COVID-19 лабораторная служба в России и зарубежных странах столкнулась с проблемами точности диагностики, получением ложноотрицательных, ложноположительных и сомнительных результатов $[13,14]$.

Цель работы - анализ литературных источников по вопросам получения ошибочных результатов ПЦР-исследований клинического материала на COVID-19, а также проблеме возникновения контаминации в лабораториях, выполняющих исследования клинического материала на наличие PHK нового коронавируса SARS-CoV-2 методом ПЦР в период пандемии COVID-19.

Материалы и методы. Поиск источников литературы осуществлялся в базах eLibrary, Google Scholar, PubMed, Science Direct, Scopus по ключевым словам: «ложноположительные и ложноотрицательные результаты ПЦР на наличие РНК вируса SARS-CoV-2», «ДНК-контаминация при исследовании на наличие вируса SARS-CoV-2», «ошибки ПЦР-диагностики COVID-19». Для анализа отобраны российские и зарубежные статьи, опубликованные на английском языке в течение 2019-2020 гг., посвященные вопросам лабораторной диагностики новой коронавирусной инфекции, работы, рассматривающие проблемы лабораторной диагностики методом ПЦР SARS и MERS и общие проблемы ДНК-контаминации в ПЦР-лаборатории (2012-2020 гг.). Также проанализирована действующая нормативно-методическая 
документация, регламентирующая проведение лабораторной диагностики новой коронавирусной инфекции методом ПЦР

Результаты. Причины получения ложноположительных и ложноотрицательных результатов исследования методом ПЦР на наличие РНК вируса SARS-CoV-2

Ошибочные результаты ПЦР могут быть связаны с неправильным отбором клинических образцов, нарушениями температурного режима при хранении и передаче образцов в лабораторию. Качество выделенного препарата РНК также влияет на точность результата ПЦР. Так, деградация образцов РНК, а также наличие ингибиторов ОТ-ПЦР в реакционной смеси могут привести к ложноотрицательным результатам [15, 16]. Перекрестное загрязнение образцов (контаминация) в процессе отбора, при проведении выделения РНК, внесения проб в реакционную смесь для ПЦР - основная причина ложноположительных результатов. В соответствии с данными, представленными в зарубежных публикациях, доля ложноположительных результатов при проведении исследований клинического материала методом ПЦР на наличие PHK коронавируса SARS-CoV-2 составляет $0,8-4,0 \%$ [17-20].

Последствия ошибок лабораторной диагностики всегда значительны, однако в период пандемии COVID-19 при массовых обследованиях их негативное влияние на эффективность работы систем здравоохранения и эпидемического надзора существенно усиливается. Ложноотрицательные результаты являются фактором, способствующим несвоевременным изоляции носителей вируса и введению ограничительных мер.

Негативное влияние ложноположительных результатов заключается в получении некорректных (завышенных) данных об уровне заболеваемости COVID-19, безосновательной изоляции или госпитализации неинфицированных лиц, что увеличивает нагрузку на медицинский персонал и лабораторную службу [21, 22]. Госпитализация неинфицированных лиц в связи с ложноположительными результатами ПЦР на SARS-CoV-2 значительно повышает риск их инфицирования в стационаре.

Контаминация нуклеиновыми кислотами (HK) - одна из проблем, возникающая при выполнении ПЦР-исследований, приводящая к ложноположительным результатам тестирования и связанная с высокой чувствительностью метода и особенностями методики постановки анализа. Проведение массового обследования населения на COVID-19 в период пандемии способствовало резкому увеличению нагрузки на лаборатории, выполняющие ПЦР. Поступление и накопление в лаборатории большого количества образцов клинического материала, увеличение объемов медицинских отходов, в т. ч. содержащих продукты амплификации, - основные причины, повышающие риск возникновения контаминации.

Основными источниками контаминации, приводящей к возникновению ложноположительных результатов, являются продукты ПЦР (ДНКампликоны), исследуемые пробы, содержащие целевую РНК (нативный материал, выделенная PHК/кДНК), а также положительные контрольные образцы, представляющие собой препараты рекомбинантной ДНК/РНК со встроенным участком гена-мишени, детектируемого диагностической ПЦР-тест-системой.

Выделяют перекрестную контаминацию механический занос целевой НК из одной пробирки в другую в процессе пробоподготовки, выделения НК, внесения пробы в реакционную смесь и тотальную контаминацию - загрязнение поверхностей и воздуха лаборатории ампликонами.

Причины возникновения контаминации в лаборатории при проведении лабораторной диагностики COVID-19 методом ПЦР

Выполнение большого объема диагностических исследований на основе ПЦР, что имеет место при массовом обследовании населения на COVID-19, характеризуется повышенным риском контаминации на всех этапах анализа.

Преаналитическая стадия лабораторного исследования является основным источником ошибок в лаборатории, в т. ч. при проведении ПЦР [15]. На стадии отбора материала причиной контаминации может являться нарушение техники отбора проб (в т. ч. использование нестерильных медицинских инструментов, загрязненных перчаток), приводящее к механическому заносу нативного материала, содержащего РНК вируса SARS-CoV-2, в другие пробы. Исследование смывов с поверхностей и проб воздуха в помещениях «красной зоны» инфекционных стационаров, осуществляющих лечение больных с COVID-19 в Китае, показало наличие РНК коронавируса SARS-CoV-2 в образцах, отобранных в 56,7 \% помещений [23-25].

На этапах первичной подготовки и обеззараживания образцов, выделения РНК, внесения проб РНК/кДНК и контрольных образцов в реакционную смесь для проведения реакции обратной транскрипции и ПЦР перекрестная контаминация возникает вследствие несоблюдения техники выполнения лабораторных манипуляций (ошибки пипетирования, касание одноразовым наконечником внутренних поверхностей пробирок, отсутствие смены перчаток при выполнении работ на разных этапах ПЦР и др.) [26].

Тотальная контаминация возникает при загрязнении рабочих зон лаборатории, оборудования и одежды сотрудников ампликонами, следами геномной РНК, попадающими в воздух лабораторных помещений, на лабораторную мебель и оборудование из пробирок и планшетов с продуктами ПЦР, с рук операторов и распространяюшимися по всем рабочим зонам лаборатории. Наиболее частым источником тотальной контаминации являются случайно открывшиеся пробирки с продуктами ПЦР [26]. Другой причиной тотальной контаминации может являться процесс инактивации ампликонов путем автоклавирования (в случае нарушения целостности пакетов для автоклавирования) ${ }^{1}$.

В зарубежных публикациях описана контаминация реактивов целевыми геномными последовательностями вируса SARS-CoV-2 в процессе производства диагностических наборов. Ряд лабораторий, выполняющих исследования на наличие PHK коронавируса SARS-CoV-2, в странах Европы и США сообщили о контаминации изготовленных на заказ партий праймеров и зондов геномными последовательностями нового коронавируса, что привело к ложноположительным результатам ПЦР. Специфическая флуоресценция отмечалась

\footnotetext{
1 Основы полимеразной цепной реакции (ПЦР). Методическое пособие (ДНК-технология). М., 2012. Доступно по: https://www.dna-technology.ru/sites/default/files/pcr_a5_083-4.pdf Ссылка активна на 10 сентября 2020 г.
} 
при проведении амплификации реакционных смесей без внесения матрицы и с внесением отрицательного контрольного образца. Степень загрязнения реакционных смесей в лабораториях существенно различалась, зарегистрированные значения порогового цикла $(\mathrm{Ct})$ составляли от 23 до 39. Анализ потенциальных источников контаминации исключил возможность попадания целевой НК в реакционную смесь вследствие ошибок при проведении манипуляций в лаборатории. Контаминация реакционных смесей для проведения исследований методом ПЦР на наличие PHK вируса SARS-CoV-2 привела к задержке получения результатов тестирования клинического материала на 2-14 дней [27].

Для обеспечения высокого уровня диагностической точности настоятельно рекомендуется предварительно тестировать каждую партию диагностических наборов для ПЦР с использованием отрицательных контрольных образцов с целью исключения контаминации реакционных смесей [27].

Признаки контаминации в лаборатории при проведении диагностики СОVID-19 методом ПЦИР

Анализ накопленного опыта по проведению диагностики COVID-19 методом ПЦР с использованием различных диагностических тест-систем (в т. ч.: «Вектор-ПЦРрв-2019-nCov-RG» (ФБУН ГНЦ ВБ «Вектор» Роспотребнадзора), «АмплиТест SARS-CoV-2» (ФГБУ «ЦСП» Минздрава России), «АмплиСенс CoV-Bat-FL» (ФБУН ЦНИИЭ Роспотребнадзора), «COVID-19 Amp» (ФБУН «НИИ эпидемиологии и микробиологии имени Пастера»)) позволил выявить основные признаки контаминации в лаборатории, выполняющей ПЦР, и предложить тактику проведения дополнительных исследований для верификации полученных результатов при подозрении на контаминацию.

Основные признаки контаминации в лаборатории, выполняющей исследования методом ПЦР, и необходимые действия при возникновении ситуации следующие.

1. Выявление положительного сигнала в отрицательном контрольном образце этапа выделения свидетельствует о загрязнении исследуемых образцов целевой РНК, или положительным нативным материалом, или положительным контрольным образцом на этапах первичной пробоподготовки, обеззараживания образцов или выделения РНК. Необходимо повторное исследование всех положительных образцов, начиная с этапа выделения PHK.

2. Выявление положительного сигнала в отрицательном контрольном образце этапа амплификации свидетельствует о загрязнении реакционной смеси на этапе ее приготовления или внесения образцов в реакционную смесь для ПЦР. Необходимо повторное исследование всех положительных образцов, начиная с этапа постановки ПЦР.

3. Существенное увеличение (в 1,5-2 раза и более) доли положительных образцов по сравнению с ожидаемой в обследуемой группе (регионе), в особенности числа проб с низкой нагрузкой целевой НК со значениями $\mathrm{Ct}>30$, может свидетельствовать о кросс-контаминации на любом из этапов анализа. Необходимо выборочное повторное исследование положительных образцов, начиная с этапа выделения РНК, в т. ч. с использованием альтернативных ПЦР-тест-систем (с праймерами на другие РНК-мишени) [2, 3].

4. Получение положительного результата для 90-100 \% образцов, включая отрицательные контроли этапов выделения и амплификации, свидетельствует о загрязнении реакционной смеси для ПЦР целевой НК. Необходимо проведение повторного тестирования проб, начиная с этапа постановки ПЦР. Повторное получение положительного результата для всех исследуемых и контрольных образцов является признаком тотальной контаминации в лаборатории. Необходимо проведение полномасштабных деконтаминационных мероприятий [3]. В случае загрязнения рабочих зон лаборатории ампликонами при отсутствии возможности остановить проведение лабораторных исследований необходимо тестировать образцы с помощью альтернативных ПЦР-тест-систем.

5. Получение положительного результата при исследовании контрольных смывов, выполняемых в соответствии с действующими нормативными документами для контроля контаминации в лаборатории, осуществляющей диагностические исследования методом ПЦР, требует проведения дополнительных мероприятий по ликвидации контаминации.

Необходимо отметить, что в случае контаминации образцов нативным материалом на этапе первичной пробоподготовки образцов повторное тестирование проб, в т. ч. с использованием альтернативных наборов реагентов, также покажет положительный результат. Предположить возникновение перекрестной контаминации образцов на этапе пробоподготовки можно в случае получения отрицательного ответа при исследовании образцов клинического материала от больного после повторного забора материала.

Мероприятия, направленные на недопущение возникновения контаминации в лаборатории, и мероприятия по ликвидации последствий контаминации описаны в МУ 1.3.2569-092.

Мероприятия, препятствующие возникновению контаминации в лаборатории, выполняющей ПЦР, в т. ч. при проведении диагностики СОVID-19, включают:

- выделение отдельных рабочих зон для различных этапов анализа в лаборатории, в особенности выделение отдельного помещения для проведения амплификации, автоклавирование продуктов амплификации в отдельной зоне;

- соблюдение поточности движения исследуемого материала и медицинских отходов, в т. ч. пробирок с ампликонами;

- обязательную постановку отрицательных контролей на этапах выделения и амплификации;

- строгое соблюдения порядка внутрилабораторного контроля качества (исследование смывов с лабораторных поверхностей и оборудования с целью контроля контаминации, выборочное повторное тестирование образцов);

- соблюдение техники пипетирования, использование одноразового стерильного пластикового расходного материала (наконечников для дозаторов, микропробирок), наконечников с фильтром на этапах работы с нативным материалом, РНК, кДНК, перчаток и отдельных комплектов защитной одежды в каждой рабочей зоне, обработку рук, правильное пипетирование жидкостей.

${ }^{2}$ МУ 1.3.2569-09 «Организация работы лабораторий, использующих методы амплификации нуклеиновых кислот при работе с материалом, содержащим микроорганизмы I-IV групп патогенности». Утв. руководителем Федеральной службы по надзору в сфере защиты прав потребителей и благополучия человека, главным государственным санитарным врачом Российской Федерации Г.Г. Онищенко 22 декабря 2009 г. Введены в действие с 5 апреля 2010 г.

VolUmE 2Q, ISUE 7, 2021 


\section{Мероприятия по ликвидации контаминации в лаборатории:}

- расходный материал, реактивы, защитную одежду в контаминированной зоне утилизируют;

- проводят обработку рабочих и лабораторных поверхностей с использованием дезинфицирующих средств $(0,2 \%$ ДП-2Т) или реактивов для разрушения ДНК (DNA-exitusplus (AppliChem) и аналогичные) с экспозицией 30 мин, по окончании которой остатки дезинфектанта тщательно удаляют смоченной в воде ветошью;

- проводят обеззараживание рабочих и лабораторных поверхностей ультрафиолетовым излучением в течение 45 мин;

- вышеуказанные манипуляции по обработке повторяют дважды;

- исследуют смывы с лабораторных поверхностей и оборудования с целью контроля контаминации.

При соблюдении всех требований, указанных в МУ 1.3.2569-09, вероятность возникновения ДНК контаминации в лаборатории минимальна. Порядок проведения деконтаминационных мероприятий, описанный в МУ, позволяет в короткие сроки ликвидировать контаминацию.

Повышенный риск контаминации в лабораториях, выполняющих большое количество анализов на COVID-19, обусловливает необходимость постоянного контроля за выполнением требований МУ1.3.2569-09.

Причины возникновения ложноположительных результатов ПЦР, не связанные с контаминацией

Ложноположительные результаты исследования при проведении ПЦР могут быть связаны не только с контаминацией проб (реактивов) и возникать вследствие образования неспецифических продуктов ПЦР или неспецифической флуоресценции реакционной смеси.

Вероятность образования неспецифических продуктов ПЦР повышается на поздних циклах термоциклирования. Их появление может быть связанно с завышенной концентрацией праймеров, возникающей вследствие неправильного приготовления смеси для ПЦР, ошибками в программировании прибора для проведения ПЦР в реальном времени.

При учете результатов ПЦР для дифференциации положительного сигнала и образовании неспецифического продукта реакции необходимо оценивать форму кривой флуоресценции (кривая должна быть S-образная, со значением флуоресценции в стадии плато, сопоставимым со значением максимального уровня флуоресценции положительного контрольного образца).

Эффект неспецифической флуоресценции реакционной смеси связан с ошибками приготовления реакционной смеси (неправильное соотношение компонентов, приводящее к изменению концентрации праймеров) либо неправильным хранением ПЦР-смеси до внесения проб (длительное хранение при комнатной температуре), приводящим к деградации зондов. Эффект неспецифической флуоресценции отличается от признаков контаминации одинаковым уровнем флуоресценции всех проб, что редко наблюдается при контаминации, поскольку маловероятно, что во все пробирки попадет одинаковое количество специфических ампликонов $^{3}$. Для решения проблемы неспецифической флуоресценции необходимо соблюдать температурные условия хранения тест-систем, размораживать реактивы и готовить реакционную смесь непосредственно перед постановкой ПЦР.

Заключение. Проблема контаминации в лабораториях, выполняющих ПЦР, при диагностике COVID-19 обострилась в связи с необходимостью проведения большого объема исследований. Негативные последствия контаминации нуклеиновыми кислотами заключаются в получении ложноположительных ответов, необходимости останавливать проведение лабораторных исследований на время проведения и контроля деконтаминационных мероприятий.

Для минимизации риска возникновения контаминации в условиях массового скрининга на COVID-19 следует строго соблюдать поточность движения исследуемого материала и медицинских отходов, в особенности пробирок, содержащих продукты ПЦР. Важную роль в предотвращении контаминации играет организация внутрилабораторного контроля качества, включающего обязательную постановку отрицательных контролей выделения и амплификации, проведение плановых контрольных исследований для выявления контаминации и строгий контроль выполнения таких мероприятий.

Для снижения вероятности появления ложноположительных результатов целесообразно проводить выборочное подтверждающее тестирование положительных проб с использованием альтернативных ПЦР-тест-систем для выявления PHK SARS-CoV-2

Действующие MУ 1.3.2569-09 подробно описывают требования к организации лабораторий, занимающихся молекулярно-генетическими и диагностическими исследованиями на основе ПЦР, а также требования к проведению работ c НK, направленные на предотвращение контаминации и ликвидацию ее последствий.

\section{Список литературы}

1. Adhikari SP, Meng S, Wu YJ, et al. Epidemiology, causes, clinical manifestation and diagnosis, prevention and control of coronavirus disease (COVID-19) during the early outbreak period: a scoping review. Infect Dis Poverty. 2020;9(1):29. doi: $10.1186 / \mathrm{s} 40249-020-00646-\mathrm{X}$

2. Lv M, Luo X, Estill J, et al. Coronavirus disease (COVID-19): a scoping review. Euro Surveill. 2020;25(15):2000125. doi: 10.2807/1560-7917.ES.2020.25.15.2000125

3. Afzal A. Molecular diagnostic technologies for COVID-19: Limitations and challenges. J Adv Res. 2020;26:149-159. doi: $10.1016 /$ j.jare.2020.08.002

4. Brooks ZC, Das S. COVID-19 testing: impact of prevalence, sensitivity, and specificity on patient risk and cost. Am J Clin Pathol. 2020;154(5):575-584 doi: 10.1093/ajcp/aqaa141

5. Ji T, Liu Z, Wang G, et al. Detection of COVID-19: A review of the current literature and future perspectives. Biosens Bioelectron. 2020;166:112455. doi: 10.1016/j. bios.2020.112455

6. Shen M, Zhou Y, Ye J, et al. Recent advances and perspectives of nucleic acid detection for coronavirus. J Pharm Anal. 2020;10(2):97-101. doi: 10.1016/j.jpha.2020.02.010

7. Coronaviridae Study Group of the International Committee on Taxonomy of Viruses. The species Severe acute respiratory syndrome-related coronavirus: classifying 2019-nCoV and naming it SARS-CoV-2. Nat Microbiol. 2020;5(4):536-544. doi: $10.1038 / \mathrm{s} 41564-020-0695-\mathrm{z}$

8. Espy MJ, Uhl JR, Sloan LM, et al. Real-time PCR in clinical microbiology: applications for routine laboratory testing. Clin Microbiol Rev. 2006;19(1):165-256. doi: 10.1128/CMR.19.1.165-256.2006

9. Corman VM, Landt O, Kaiser M, et al. Detection of 2019 novel coronavirus (2019-nCoV) by real-time RT-PCR. Euro Surveill. 2020;25(3):2000045. doi: 10.2807/1560-7917. ES.2020.25.3.2000045

10. Corman VM, Müller MA, Costabel U, et al. Assays for laboratory confirmation of novel human coronavirus

\footnotetext{
${ }^{3}$ Основы полимеразной цепной реакции (ПЦР). См. выше.
} 
Original article

(hCoV-EMC) infections. Euro Surveill. 2012;17(49):20334. doi: 10.2807/ese.17.49.20334-en

11. Wang W, Xu Y, Gao R, et al. Detection of SARSCoV-2 in different types of clinical specimens. JAMA 2020;323(18):1843-1844. doi: 10.1001/jama.2020.3786

12. Pascarella G, Strumia A, Piliego C, et al. COVID-19 diagnosis and management: a comprehensive review. J Intern Med. 2020;288(2):192-206. doi: 10.1111/joim.13091

13. Watson J, Whiting PF, Brush JE. Interpreting a COVID-19 test result. BMJ. 2020;369:m1808. doi: 10.1136/bmj.m1808

14. Tahamtan A, Ardebili A. Real-time RT-PCR in COVID-19 detection: issues affecting the results. Expert Rev Mol Diagn 2020:20(5):453-454 doi: 10.1080/14737159.2020.1757437

15. Lippi G, Simundic AM, Plebani M. Potential preanalytical and analytical vulnerabilities in the laboratory diagnosis of coronavirus disease 2019 (COVID-19). Clin Chem Lab Med. 2020;58(7):1070-1076. doi: 10.1515/cclm-2020-0285

16. van Zyl G, Maritz J, Newman H, Preiser W. Lessons in diagnostic virology: expected and unexpected sources of error. Rev Med Virol. 2019;29(4):e2052. doi: 10.1002/rmv.2052

17. Mögling R, Meijer A, Berginc N, et al. Delayed laboratory response to COVID-19 caused by molecular diagnostic contamination. Emerg Infect Dis. 2020;26(8):1944-1946. doi: $10.3201 /$ eid2608.201843

18. Willman D. Contamination at CDC lab delayed rollout of coronavirus tests. Published on Apr 18 2020. https:// www.washingtonpost.com/investigations/contamination-atcdc-lab-delayed-rollout-of-coronavirus-tests/2020/04/18/ fd7d3824-7139-11ea-aa80-c2470c6b2034_story.html

19. Cohen AN, Kessel B. False positives in reverse transcription PCR testing for SARS-CoV-2 [Preprint]. doi: 10.1101/2020.04.26.20080911

20. Lan L, Xu D, Ye G, et al. Positive RT-PCR test results in patients recovered from COVID-19. JAMA. 2020; 323(15):1502-1503. doi: 10.1001/jama.2020.2783

21. Surkova E, Nikolayevskyy V, Drobniewski F. False-positive COVID-19 results: hidden problems and costs. Lancet Respir Med. 2020;8(12):1167-1168. doi: 10.1016/S22132600(20)30453-7

22. Healy B, Khan A, Metezai H, Blyth I, Asad H. The impact of false positive COVID-19 results in an area of low prevalence. Clin Med (Lond). 2021;21(1):e54-e56. doi: 10.7861/clinmed.2020-0839

23. Chia PY, Coleman KK, Tan YK, et al. Detection of air and surface contamination by SARS-CoV-2 in hospital rooms of infected patients. Nat Commun. 2020;11(1):2800. doi: 10.1038/s41467-020-16670-2

24. Ong SWX, Tan YK, Chia PY, et al. Air, surface environmental, and personal protective equipment contamination by severe acute respiratory syndrome coronavirus 2 (SARS-CoV-2) from a symptomatic patient. JAMA. 2020;323(16):1610-1612. doi: 10.1001/jama.2020.3227

25. Lv J, Yang J, Xue J, Zhu P, Liu L, Li S. Detection of SARS-CoV-2 RNA residue on object surfaces in nucleic acid testing laboratory using droplet digital PCR. Sci Total Environ. 2020;742:140370. doi: 10.1016/j.scitotenv.2020.140370

26. Туполева Т.А., Тихомиров Д.С., Грумбкова Л.О. и др. Контаминация при ПЦР-исследованиях: проблемы и решения // Клиническая лабораторная диагностика. 2015. № 1. Доступно 11 сентября 2020 г. URL: https://cyberleninka.ru/article/n/kontaminatsiya-pri-tsprissledovaniyah-problemy-i-resheniya.

27. Wang CYT, Buckley C, Bletchly C, Harris P, Whiley D. Contamination of SARS-CoV-2 RT-PCR probes at the oligonucleotide manufacturer. Pathology. 2020;52(7):814-816. doi: $10.1016 /$ j.pathol.2020.08.002

\section{References}

1. Adhikari SP, Meng S, Wu YJ, et al. Epidemiology, causes, clinical manifestation and diagnosis, prevention and control of coronavirus disease (COVID-19) during the early outbreak period: a scoping review. Infect Dis Poverty. 2020;9(1):29. doi: 10.1186/s40249-020-00646-x

2. Lv M, Luo X, Estill J, et al. Coronavirus disease (COVID-19): a scoping review. Euro Surveill. 2020;25(15):2000125. doi: 10.2807/1560-7917.ES.2020.25.15.2000125

3. Afzal A. Molecular diagnostic technologies for COVID-19: Limitations and challenges. J Adv Res. 2020;26:149-159. doi: $10.1016 /$ j.jare.2020.08.002

4. Brooks ZC, Das S. COVID-19 testing: impact of prevalence, sensitivity, and specificity on patient risk and cost. Am J Clin Pathol. 2020;154(5):575-584. doi: 10.1093/ajcp/aqaa141

5. Ji T, Liu Z, Wang G, et al. Detection of COVID-19: A review of the current literature and future perspectives.
Biosens Bioelectron. 2020;166:112455. doi: 10.1016/j. bios. 2020.112455

6. Shen M, Zhou Y, Ye J, et al. Recent advances and perspectives of nucleic acid detection for coronavirus. J Pharm Anal. 2020;10(2):97-101. doi: 10.1016/j.jpha.2020.02.010

7. Coronaviridae Study Group of the International Committee on Taxonomy of Viruses. The species Severe acute respiratory syndrome-related coronavirus: classifying 2019-nCoV and naming it SARS-CoV-2. Nat Microbiol. 2020;5(4):536-544. doi: $10.1038 / \mathrm{s} 41564-020-0695-\mathrm{z}$

8. Espy MJ, Uhl JR, Sloan LM, et al. Real-time PCR in clinical microbiology: applications for routine laboratory testing. Clin Microbiol Rev. 2006;19(1):165-256. doi: 10.1128/CMR.19.1.165-256.2006

9. Corman VM, Landt O, Kaiser M, et al. Detection of 2019 novel coronavirus (2019-nCoV) by real-time RT-PCR Euro Surveill. 2020;25(3):2000045. doi: 10.2807/1560-7917. ES.2020.25.3.2000045

10. Corman VM, Müller MA, Costabel U, et al. Assays for laboratory confirmation of novel human coronavirus (hCoVEMC) infections. Euro Surveill. 2012;17(49):20334. doi: 10.2807/ese.17.49.20334-en

11. Wang W, Xu Y, Gao R, et al. Detection of SARSCoV-2 in different types of clinical specimens. JAMA. 2020;323(18):1843-1844. doi: 10.1001/jama.2020.3786

12. Pascarella G, Strumia A, Piliego C, et al. COVID-19 diagnosis and management: a comprehensive review. Intern Med. 2020;288(2):192-206. doi: 10.1111/joim.13091

13. Watson J, Whiting PF, Brush JE. Interpreting a COVID-19 test result. BMJ. 2020;369:m1808. doi: 10.1136/bmj.m1808

14. Tahamtan A, Ardebili A. Real-time RT-PCR in COVID-19 detection: issues affecting the results. Expert Rev Mol Diagn. 2020;20(5):453-454. doi: 10.1080/14737159.2020.1757437

15. Lippi G, Simundic AM, Plebani M. Potential preanalytical and analytical vulnerabilities in the laboratory diagnosis of coronavirus disease 2019 (COVID-19). Clin Chem Lab Med. 2020;58(7):1070-1076. doi: 10.1515/cclm-2020-0285

16. van Zyl G, Maritz J, Newman H, Preiser W. Lessons in diagnostic virology: expected and unexpected sources of error. Rev Med Virol. 2019;29(4):e2052. doi: 10.1002/ rmv. 2052

17. Mögling R, Meijer A, Berginc N, et al. Delayed laboratory response to COVID-19 caused by molecular diagnostic contamination. Emerg Infect Dis. 2020;26(8):1944-1946. doi: $10.3201 /$ eid2608.201843

18. Willman D. Contamination at CDC lab delayed rollout of coronavirus tests. Published on Apr 18 2020. https:// www.washingtonpost.com/investigations/contamination-at-cdc-lab-delayed-rollout-of-coronavirus-tests/2020/04/18/ fd7d3824-7139-11ea-aa80-c2470c6b2034 story.html

19. Cohen AN, Kessel B. False positives in reverse transcription PCR testing for SARS-CoV-2 [Preprint]. doi: 10.1101/2020.04.26.20080911

20. Lan L, Xu D, Ye G, et al. Positive RT-PCR test results in patients recovered from COVID-19. JAMA. 2020;323(15):1502-1503. doi: 10.1001/jama.2020.2783

21. Surkova E, Nikolayevskyy V, Drobniewski F. False-positive COVID-19 results: hidden problems and costs. Lancet Respir Med. 2020;8(12):1167-1168. doi: 10.1016/S22132600(20)30453-7

22. Healy B, Khan A, Metezai H, Blyth I, Asad H. The impact of false positive COVID-19 results in an area of low prevalence. Clin Med (Lond). 2021;21(1):e54-e56. doi: 10.7861/clinmed.2020-0839

23. Chia PY, Coleman KK, Tan YK, et al. Detection of air and surface contamination by SARS-CoV-2 in hospital rooms of infected patients. Nat Commun. 2020;11(1):2800. doi: $10.1038 / \mathrm{s} 41467-020-16670-2$

24. Ong SWX, Tan YK, Chia PY, et al. Air, surface environmental, and personal protective equipment contamination by severe acute respiratory syndrome coronavirus 2 (SARS-CoV-2) from a symptomatic patient. JAMA 2020;323(16):1610-1612. doi: 10.1001/jama.2020.3227

25. Lv J, Yang J, Xue J, Zhu P, Liu L, Li S. Detection of SARS-CoV-2 RNA residue on object surfaces in nucleic acid testing laboratory using droplet digital PCR. Sci Total Environ. 2020;742:140370. doi: 10.1016/j.scitotenv.2020.140370

26. Tupoleva TA, Tikhomirov DS, Grumbkova LO, et al. The contamination under polymerase chain reaction studies: problems and solutions. Klinicheskaya Laboratornaya Diagnostika. 2015;(1):39-42. (In Russ.)

27. Wang CYT, Buckley C, Bletchly C Harris $\mathrm{P}$, Whiley D. Contamination of SARS-CoV-2 RT-PCR probes at the oligonucleotide manufacturer. Pathology. 2020;52(7):814-816. doi: $10.1016 /$ j.pathol.2020.08.002 